\title{
Identidad Digital, ser, estar y actuar en la red
}

\author{
Isabel Gutiérrez Porlán \\ Universidad de Murcia \\ isabelgp@um.es
}

"Si su negocio no está en Internet, su negocio no existe".

Bill Gates.

¿Es posible hablar hoy en día de Identidad y que ésta no tenga ningún componente de la esfera digital? ¿Es posible no tener ninguna presencia en la red?

Ya hace casi 30 años de la polémica y controvertida afirmación de Bill Gates "si su negocio no está en la red, su negocio no existe", y aunque con matizaciones, es una afirmación que ya no nos parece tan descabellada.

En relación al mundo de los negocios, las empresas, organizaciones e instituciones tienen cada vez más una importante presencia en la red. Estas organizaciones que tienen un objetivo 0 meta saben de la importancia de su presencia en red, tanto que todo lo relacionado con el marketing digital se ha convertido en una de las competencias profesionales más demandadas hoy en día.

La afirmación de Bill Gates, realizada en los años 80 , con la presencia de los medios sociales de los que disponemos hoy en día, debería modificarse por "si tu negocio no es, está y actúa en la red, tu negocio no existe". Los medios sociales son el corazón de la cultura contemporánea y son ya una parte cotidiana de la vida. Estos medios nos ofrecen un espacio de expresión y una oportunidad de participación que, por evidentes limitaciones, no nos permite el entorno presencial (Boyd, 2014).

Los medios sociales cobran sentido por la participación, los usuarios que demandan información a través de la red esperan una respuesta rápida por parte la empresa, organización e institución a la que se dirigen. Por tanto, aquellas organizaciones que solo están pero no participan en la red es como si no estuvieran. Los medios sociales hacen que las organizaciones tengan que dar un paso más porque en la participación con los usuarios está la esencia de que éstas estén en red.

Además de lo anterior, la Identidad Digital no solo se compone de aquello que nosotros publicamos en la red, hay una parte muy importante de dicha identidad que se configura por lo que otros dicen de nosotros en red, no es solo lo que hacemos, sino quien nos influencia y a quién influenciamos (Castañeda y Camacho, 2012). Por tanto, las empresas y organizaciones ya no solo se preocupan por aquello que ellas dicen en red, sino por lo que los demás dicen de ellas. Para los usuarios son más importantes las recomendaciones de otros usuarios que lo que la propia empresa te cuenta o vende y aunque estos aspectos son más difíciles de controlar es algo que también debe tenerse en cuenta. 
En este sentido la revista RIITE lleva desde sus orígenes haciendo una fuerte apuesta por su Identidad Digital, no solo con su presencia en distintos medios sociales sino con una participación activa en dichos medios. Es posible encontrar e interactuar con la revista RIITE desde sus cuentas en:

- Twitter: @revistaRIITE

- Facebook: https://www.facebook.com/RevistaRIITE/

- Youtube: https://goo.gl//bm5n1g

Puesto que uno de los compromisos y señas de identidad de RIITE es apoyar al investigador novel en todas las fases del proceso de investigación, también involucra al mismo en el proceso de difusión y trasferencia de la misma. RIITE hace partícipe a sus autores y lectores a través de muchos medios con los que pretende dar voz a los verdaderos protagonistas de la investigación. Así pues, se está poniendo en marcha la \#comunidadRITE con la que se pretende dar un salto en los aspectos referidos a la participación y realmente crear una comunidad de la revista en la que existan múltiples formas de participar tanto para los propios autores, como para los lectores o actuando como crítico de los artículos publicados y siendo altavoz y difusor de los trabajos publicados. Algunas de las formas de participación que ya se han puesto en marcha son:

- Vídeo-reseñas de artículos: en las que se hace una breve reseña de un artículo publicado (https://goo.gl/BIr4aR)

- Infografías: en las que se presenta de forma clara y visual el contenido del artículo (https://es.pinterest.com/revistariite/)

En la misma línea de fomentar la participación, RIITE publica en cada número una entrevista a alguien relevante en el ámbito de la investigación en Tecnología Educativa. En este número tenemos el inmenso placer de contar con la participación de George Veletsianos, Catedrático y Director de Investigación sobre "Aprendizaje innovador y Tecnología" de la Royal Roads University, en Victoria BC (Canadá). Su investigación se centra en la comprensión y la mejora de la enseñanza y el aprendizaje en entornos digitales emergentes. En la entrevista, que os animamos a leer, tenemos la oportunidad de conocer su opinión sobre ¿cuáles son las principales tendencias que están influyendo en la tecnología educativa? y ¿cuáles son las mayores lagunas o necesidades en investigación en tecnología educativa? Podemos destacar de esta entrevista los sabios consejos que ofrece a los investigadores noveles: "aprender de lo que se ha hecho y de los resultados de la investigación".

Si la entrevista de este número es interesante, los artículos publicados también nos ofrecen diferentes perspectivas necesarias en el ámbito de la investigación en tecnología Educativa.

Por una parte, encontramos artículos relacionados con la investigación en tecnología educativa en el ámbito escolar como el presentado por Mario José Contreras Rodríguez titulado "Aplicación de un libro electrónico para el aprendizaje de la hoja de cálculo dirigido a estudiantes de sexto grado" y el presentado por Alejandro Egea, Laura Arias y Alfonso J. García titulado "Videojuegos, historia y patrimonio: primeros resultados de una investigación educativa evaluativa en educación secundaria".

De otro lado, en este número se incluye un interesante artículo de Manuel Ángel RomeroGarcía y María del Carmen Martínez-Serrano denominado "Inclusión de los medios tecnológicos en el Plan de Inspección de Andalucia" sobre la supervisión de la acción tutorial y la orientación educativa por la Inspección de Educación en dicha comunidad y el uso de los medios tecnológicos previstos en el Plan de Inspección para el curso 2016/2017. 
La investigación en el ámbito de los MOOC también tiene presencia en este número de RIITE con el artículo publicado por $\mathrm{M}^{\mathrm{a}}$ Cruz Bernal y $\mathrm{M}^{\mathrm{a}} \mathrm{Paz}$ Prendes titulado "Cursos masivos y en línea: caso de estudio longitudinal" en el que se presenta una revisión teórica sobre los MOOC y sus características, además de un análisis de estadísticas recientes que muestran la relevancia del fenómeno y a la par las altas tasas de deserción que se producen en los mismos.

Por último, los lectores pueden disfrutar de la reseña del libro "Las TIC en las Aulas Hospitalarias" realizada por la profesora Ma Ángeles Hernández Prados.

Sin más, os animo a sumergiros en este nuevo número de RIITE y sobre todo a comentar y opinar sobre él en vuestros espacios en red, sin tu participación la \#comunidadRIITE no tiene sentido así que esperamos tus aportaciones.

Referencias:

\section{REFERENCIAS BIBLIOGRÁFICAS}

Boyd, D. (2014). It's complicated. New Haven: Yale University Press.

Castañeda, L; Camacho, M. (2012). Desvelando nuestra identidad digital. El profesional de la información, 21, 4, 354-360.

\section{INFORMACIÓN SOBRE LA AUTORA}

\section{Isabel Gutiérrez Porlán}

Universidad de Murcia

Profesora Contratada Doctora en el Departamento de Didáctica y Organización Escolar de la Universidad de Murcia. Miembro del Grupo de Investigación de Tecnología Educativa. Licenciada en Pedagogía por la Universidad de Murcia. Máster en Tecnología Educativa: aprendizaje virtual y gestión del conocimiento por la Universidad de las Islas Baleares. Doctora en Tecnología Educativa por la Universidad Rovira i Virgili.

Sus principales líneas de investigación son: Competencias TIC del profesorado universitario, Redes Sociales, usos seguros y educativos, Identidad DIgital e Innovación Docente en Educación Superior.

Web personal: www.isabelgp.es

\section{$(\mathrm{Cc}) \mathrm{BY}_{\mathrm{B}-\mathrm{NO}}$}

Los textos publicados en esta revista están sujetos a una licencia de Reconocimiento 4.0 España de Creative Commons. Puede copiarlos, distribuirlos, comunicarlos públicamente y hacer obras derivadas siempre que reconozca los créditos de las obras (autoría, nombre de la revista, institución editora) de la manera especificada por los autores o por la revista. La licencia completa se puede consultar en:Licencia Creative Commons Atribución-NoComercial-Compartir por igual 4.0 Internacional. 